\title{
THE NANSEN CLOSING METHOD WITH VERTICAL PLANKTON NETS
}

\author{
By R. I. Currie and P. Foxton \\ National Institute of Oceanography, Wormley, Surrey
}

(Plates I and II and Text-figs. I and 2)

Several methods have been devised for sampling plankton in the different water layers in the ocean, but for many years vertically hauled nets closed by a method devised by Nansen (1915) have fulfilled this purpose. Recently, however, an investigation by Barnes (1949) cast doubt on the validity of this method for quantitative work, and as in his paper he specifically referred to nets of the type used on the 'Discovery' Expeditions, the present observations were conducted to determine whether Barnes's findings were of general application to the method.

The Nansen closing principle, which will be described in more detail later, employs a throttling rope which encircles the net some distance behind the mouth, and which becomes the towing line when the front towing bridles are released, and closes the net. Although the method is adaptable to almost any medium-sized net, with vertical hauls it is most frequently used with the Nansen net (Künne, 1929), and in this manner it has been employed extensively. Hjort in the Norwegian plankton investigations (Hjort \& Ruud, I927, footnote, p. 32; Murray \& Hjort, I9I2, p. 46), the 'Discovery' Expeditions in the Antarctic, the British, Australian and New Zealand Antarctic Research Expedition, the Australian, South African and many other fishery research organizations have all used the method.

More recently, in view of the claims made for the superiority of obliquely hauled nets (mostly on the grounds that they are less liable to be affected by patchiness of the plankton distribution), many workers have tended to replace the vertical net with such devices as the Clarke-Bumpus sampler and other obliquely towed apparatus (Wiborg, 1948). In the collection of zooplankton in deep oceanic waters, however, practical problems arise. Oblique hauls in several thousand metres of water become a tedious and time-consuming operation, whereas vertical hauls can conveniently be carried out at the same time as water-sampling and other such operations. Furthermore, one can be much more certain of fishing a specific depth horizon with a vertical haul.

It is also desirable in plankton collection to use standardized methods as far as is possible. This simplifies greatly the comparison between observations made by different workers, at different times and in different places. It was, 
therefore, not only with regard to the vast amount of earlier work which has been done with the method, but also in view of future work which is anticipated, that it was felt a matter of some importance to undertake the present observations.

It was originally intended to study the closing of the net in an experimental tank, watching, by means of coloured dyes or streamers, the movement of water in the net during the closing process. It was at once apparent, however, that it would be impossible to simulate in the laboratory the actual working conditions which prevail at sea. The effects of the rolling of the ship and the action of the special davit from which the net is used would be extremely difficult to reproduce in the laboratory. In view of this, it was decided that direct observation of the normal performance of the net at sea would be the only satisfactory way of studying the closing process and then a record could be made of it by means of underwater cine-photographs. Suitable opportunity for doing this occurred in September and October-November of 1955, when the R.R.S. Discovery II was working in the region of the Canary Islands. Preliminary observations were first made by swimming with face masks while the net was being operated from the ship, and later, for the underwater cinephotography, the ship went to the Salvage Islands. Here, the water was warm and exceptionally clear, presenting ideal conditions for photography, and it was possible to anchor the ship in the calm water under the lee of the islands.

As far as we are aware these photographs are the first attempt to record the performance of a plankton net under actual working conditions at sea.

\section{BARNES'S OBSERVATIONS}

The data which were analysed by Barnes (1949) were obtained by Marshall, Nicholls \& Orr (Nicholls, I933) in their study of the Clyde Sea Area in 1932. The net hauls were taken by means of a modified International net fitted with a Nansen (I9I5) closing mechanism. The net, according to Nicholls (I933), differed from the standard pattern of Ostenfeld \& Jespersen (I924) in that 'the cylindrical part of the net was made of canvas instead of netting and the conical part of fine-meshed bolting-silk ( 77 strands in I cm). An ordinary townet bucket was used. A hand winch was used for hauling the net, the rate at first being kept as nearly as possible to half a metre per second.' Dr Barnes informs us that no accumulator springs were used on the davits.

From a statistical analysis of the composition of the catches of undivided and divided hauls (divided meaning that the net was hauled through a specific depth horizon and then closed), Barnes reached the conclusion that a significant loss of catch took place from the divided haul or, in other words, when the Nansen closing method was brought into use. He illustrated this in particular from the catches of Microcalanus pygmaeus, a copepod which was present only below the level of closure of the divided haul. Of this organism 
the catches in the divided hauls were significantly less than those in the undivided hauls.

To determine the cause of this loss from the divided haul, he carried out some experiments with a model net in the mouth of which was hung a bag of powdered potassium permanganate. An electric motor was used to tow the model horizontally in a tank, and closing was simulated by stopping the motor and reducing the forward speed of the model by a line attached to the tail of the net. A colour film taken of those experiments showed that when the net was stopped the water in the net tended to flow out of the mouth of the net. Recently Motoda \& Anraku (I955) have observed this to occur with a fullscale net. Thus it seemed that in the full-scale net it must be the deceleration or falling back of the net while it closed that accounted for the loss of catch.

The net which Barnes considered, and a model of which he used in his experiments, he refers to as the 'Discovery' net. However, the measurements show that it is actually a model of the 'Discovery' phytoplankton net, the $\mathrm{N} 50 \mathrm{~V}$, a net which is practically never used with the Nansen closing mechanism. Only on a few occasions has the $\mathrm{N}_{50 \mathrm{~V}}$ ever been closed, and this only to prevent ripping of the net as it comes out of the water in very bad weather.

The net which is normally used with the Nansen closing mechanism on board the R.R.S. Discovery II is the so-called N70V. This net is larger and of much coarser mesh than the $\mathrm{N}_{50 \mathrm{~V}}$, and this fact combined with the method of operation led us to expect that its behaviour might be quite different from the International net, and models of the N50V which Barnes used.

\section{The 'Discovery' Net (N 70V)}

This net was based on that used by Hjort (Hjort \& Ruud, I927, p. 32, footnote), and is described by Kemp, Hardy \& Mackintosh (I929). It is similar to the Nansen net of Künne (I929). It is $70 \mathrm{~cm}$. in diameter at the mouth and is constructed of four sections, the first three of which are almost cylindrical while the final section tapers conically to the net bucket. The first section is of $\frac{1}{4}$ in. mesh netting, and this is followed by a canvas band bearing six brass rings through which the throttling rope is led. The third section, which is almost cylindrical, is a length of bolting-silk having 40 meshes to the linear inch, and the fourth section which tapers conically to the net bucket is a length of bolting-silk having 74 meshes to the linear inch. The net bucket has on its side a gauze window of I40 meshes to the linear inch. The throttling rope is $I 6 \frac{1}{2} \mathrm{ft}$. long, which allows 4 in. of slack when the net is properly rigged. It is threaded from the release gear down and around the canvas band and back up to the release gear, so that the net when it closes is caught up in a bight of this rope. The net is towed by three bridles, $\frac{1}{4}$ in. brass rods 32 in. long joining into a single ring which fits into the closing mechanism. Below the net is a weight of about $40 \mathrm{lb}$. supported on three phosphor-bronze stays, which 
run the full length of the net and are attached both to the net bucket and the net ring.

With the ship hove to, the net is lowered to the required depth on a wire running over a metre counter on a specially designed davit. The latter incorporates a long accumulator spring on a movable sheave (Text-fig. I). With the rolling of the ship this spring helps to keep an even strain on the wire, preventing any undue slackening as the net is paid out. On reaching the necessary depth, the steam winch is put in gear, and a messenger on a long line is clipped on the wire. Hauling is commenced, and a steady rate of $\mathrm{I} \mathrm{m} /$ $\sec$ (compared with $\frac{1}{2} \mathrm{~m} / \mathrm{sec}$ of the International net) can easily be maintained by regulating the steam valve, while a stopwatch is used to check thereadings of the metre counter. As the net is hauled upwards, the winch and accumulator spring maintain a tension on the wire to the net which never relaxes, even in the very worst weather conditions. One can be fairly certain, therefore, that the net travels upward at quite a uniform speed. At a predetermined instant the messenger is released from the line-e.g. if it is desired to close the net at $500 \mathrm{~m}$ the messenger would be released at a metre counter reading of $660 \mathrm{~m}$, since it travels at $3.12 \mathrm{~m} / \mathrm{sec}$ and would take 160 sec to reach $500 \mathrm{~m}-$ the hauling time required for $\mathrm{I} 60 \mathrm{~m}$. The closing of the net can easily be seen by a sudden drop of the accumulator sheave, and only very rarely is the depth of closure more than $\mathrm{I}-2 \%$ different from the calculated depth even on a $500 \mathrm{~m}$ haul.

As the messenger hits the release mechanism, the brass towing bridles are released, and the towing point transfers to the throttling rope which closes the net by tightening the bight behind the mouth of the net. When this takes place the accumulator spring suddenly extends, taking in the slack on the wire, while at the same instant the steam winch accelerates momentarily until the wire to the net is once more taut.

\section{The Underwater ObServations and Photographs}

For the purpose of observing the net closing underwater the ship was anchored in about 15 fathoms of water to the leeward of Selvagem Grande (in September) and Selvagem Pequena (in November). The net was fished from the port forward well-deck winch to facilitate the photography, which was controlled from a rubber dinghy, the swimmers being equipped with face masks and frogmen's feet. In a calm sea and with the ship at anchor, the net-wire led vertically into the water. It was normally paid out to $25 \mathrm{~m}$, at which depth, in the clear waters of the Salvage Islands, it was perfectly visible, and it was thus possible to observe the net throughout the whole of its operation.

To ensure that the net would close just below the surface, two large stream-lined messengers were clipped on the wire and suspended about I $\mathrm{m}$ below the surface. The bore and weight of the messengers were such that the 
wire could be hauled through them, so to speak, without any tendency for the messengers to ride up the wire out of the water. The net, on the impact of the release mechanism and messenger, closed in the normal manner. In the hope that they would indicate direction of flow, tapes were attached on crosswires inside the mouth and at several points further down the net. The movements of the tapes in the mouth were clearly seen (see Pls. I and II).

The attachment of tapes, the suspension of the messengers and the anchoring of the ship were the only deviations from the normal routine method of fishing the $\mathrm{N} 70 \mathrm{~V}$, none of which could in any way alter the performance of the net. In the course of these investigations some thirty vertical hauls were made in this manner.

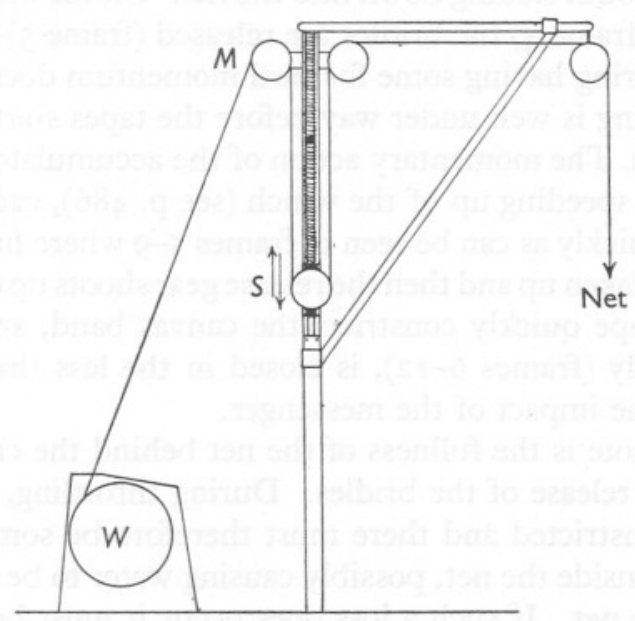

Text-fig. I. Diagrammatic arrangement of sheaves and accumulator spring on davit. $M$, measuring sheave; $S$, sliding sheave; $W$, winch.

Observations of the net as it is lowered show that both the silk section and the canvas throttling band are collapsed by the pressure of water forcing them up towards the ring, where the tapes can be seen leading upwards. The filtering part of the net is thus constricted, making it virtually impossible for the net to catch plankton on the way down. The shape of the net is, in fact, identical to that figured in Murray \& Hjort (I912, fig. 29a, p. 46). On hauling, the pressure of water fills out the net. The net rises steadily in the water until the release mechanism strikes the messengers and closing takes place. The bridles are released and the net ring starts to fall in the water; at the same time the net appears to decelerate slightly and the throttling rope tightens, closing the net, which then continues on its upward path. The closing takes but an instant and seeing it for the first time one is immediately struck by the speed and smoothness of the whole operation. 
The quickness of the throttling makes it impossible to see anything more than has just been described. Of the hauls that were made, however, some twenty were successfully photographed, including two in which the messenger was released in the normal manner (see p. 486) and allowed to run down the wire to close the net at a predetermined depth-in this case $5 \mathrm{~m}$. The resulting cine-film makes it possible to analyse and measure the sequence of events in greater detail, and Pls. I and II show a series of stills made from a typical section of the film. They are of alternate frames, the time interval between each shot being $\frac{1}{12} \mathrm{sec}$, so that the whole series represents $2 \cdot 0 \mathrm{sec}$ of the haul.

The first three frames in Pl. I show the net being hauled vertically through the water at a speed of $\mathrm{I} \mathrm{m} / \mathrm{sec}$, with the silk filtering section filled out, and the tapes in the mouth leading down into the net. On the impact of messenger and release gear (frame 4) the bridles are released (frame 5) and the net starts to close. The net ring having some forward momentum does not fall immediately, and throttling is well under way before the tapes start to fall out of the net ring (frame 7). The momentary action of the accumulator spring (p. 486), together with the speeding up of the winch (see p. 486), causes the throttling rope to tighten quickly as can be seen in frames 5-9 where first the slack in the throttling rope is taken up and then the release gear shoots up out of the picture. The throttling rope quickly constricts the canvas band, and the net, which decelerates slightly (frames 6-I2), is closed in the less than I.O sec (P1. II, frame I6) after the impact of the messenger.

Of particular note is the fullness of the net behind the canvas band which persists after the release of the bridles. During throttling, the mouth of the silk section is constricted and there must therefore be some decrease in the volume of water inside the net, possibly causing water to be expelled from the upper part of the net. If such a loss does occur it must be very small since any appreciable loss of water would cause the back section of the net to collapse very rapidly. The reverse in fact appears to occur and the action of the throttling rope seems to be to maintain or even increase the internal pressure of water in the net. Even after complete throttling there is still a considerable bulge in the silk which disappears only when the net has once more resumed its upward path through the water (frames I6-24).

The bilge keel of the ship, which is clearly shown in each frame of the sequence, provides a convenient point of reference from which it is possible to measure, and, thereby follow closely, the successive positions of the various parts of the net. Such measurements, taken from Pls. I and II, can be converted into metres using the known dimensions of the net-in this case the diameter of the ring. Text-fig. 2 shows the distances in successive frames from the bilge keel to $(a)$ the net ring, $(b)$ the throttling point, and (c) the end of the first silk section (the white horizontal band in the photographs), together with (d) the width of the end of the first silk section. This diagram confirms the previous description of the process of throttling. It will be seen that the 
filtering part of the net, represented by curves $(b)$ and $(c)$, does not drop in the water, although it does decelerate and is practically stationary for about a $\frac{1}{4} \mathrm{sec}$ (frames 8-II). It then accelerates and by the I5th frame the point of throttling has passed the falling net ring (curve $a$ ) and the net is then completely throttled. It is only then, as it is once more hauled rapidly through the water, that the bulge in the silk, represented by the width of the white band (curve $d$ ), starts to decrease. The time scale shows that complete throttling occurs about $0 \cdot 75^{-I} \cdot 0 \mathrm{sec}$ after the impact of the messenger, and similar measurements taken from two other vertical closing hauls selected at random from the film confirm this time.

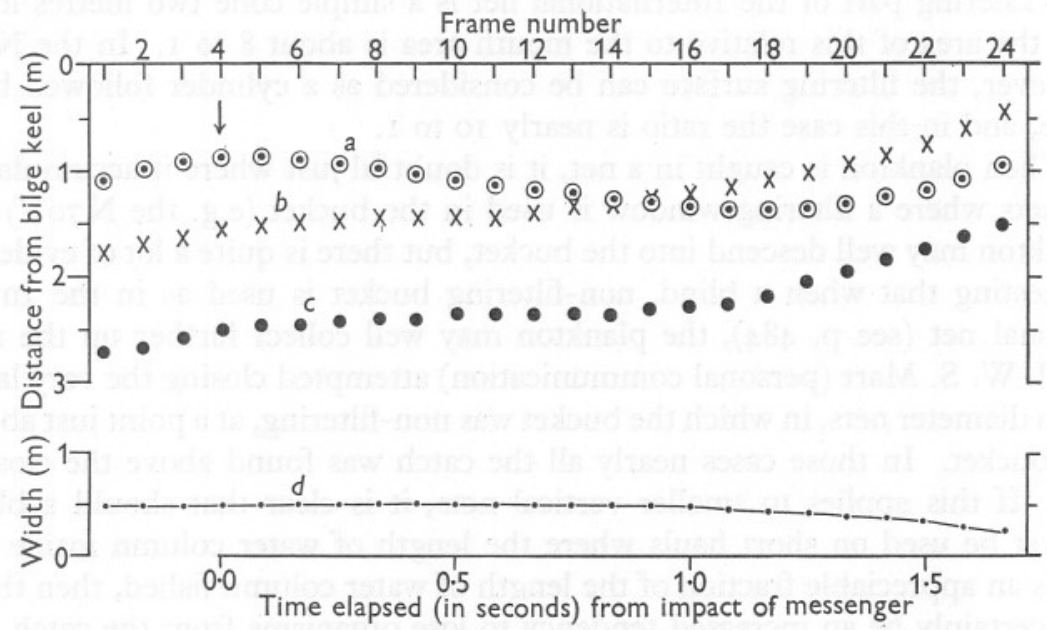

Text-fig. 2. Measurements taken from Plates I and II, showing the distance from the bilge keel of the ship to various parts of the net, plotted against time. The width of the end of the first silk filtering section is also shown. The arrow indicates the point of impact of the messenger on the release gear. $a$, net ring; $b$, throttling band; $c$, end of first silk section; $d$, width of end of first silk section.

\section{DISCUSSION}

To understand the difference in behaviour between the 'Discovery' net (the $\mathrm{N} 70 \mathrm{~V}$ ) and the modified international net used by Barnes, we must take into consideration the different construction and method of operation of the nets.

If a net has a low filtration coefficient, then only a small quantity of water actually passes through the meshes, and the water which does not escape in this way must be carried along by the net, creating a back pressure against the inflow of water at the mouth of the net. As the filtration coefficient increases, so more water escapes through the meshes and the back pressure must reduce until it reaches zero at $100 \%$ filtration coefficient.

Suppose now that the net is stopped instantly, there will be a tendency for any back pressure to manifest itself in an outflow of water from the mouth 
of the net, and this tendency will become greater the lower the filtration coefficient is. It is, therefore, a point of great importance that the $\mathrm{N} 70 \mathrm{~V}$ with its relatively wide mesh (40-74 meshes/in. compared with 200 meshes/in. of the International net) has a very much higher filtration coefficient than the fine-meshed International net. We have made experiments in which vertical hauls were made with a flow-meter mounted in a net of the N70V type and compared with hauls in which the meter alone was used, and these show that the filtration coefficient of the 'Discovery' net is of the order of $80-90 \%$. Not only does the filtration coefficient depend on the mesh of the net, but also on the ratio of the area of the filtering surface to that of the mouth opening. The filtering part of the International net is a simple cone two metres long, and the area of this relative to the mouth area is about 8 to I. In the N70, however, the filtering surface can be considered as a cylinder followed by a cone, and in this case the ratio is nearly Io to I.

When plankton is caught in a net, it is doubtful just where it accumulates. In nets where a filtering window is used in the bucket (e.g. the $\mathrm{N}_{70} \mathrm{~V}$ ) the plankton may well descend into the bucket, but there is quite a lot of evidence suggesting that when a blind, non-filtering bucket is used as in the International net (see p. 484), the plankton may well collect farther up the net. $\mathrm{Mr}$ J. W. S. Marr (personal communication) attempted closing the very large $4 \frac{1}{2} \mathrm{~m}$ diameter nets, in which the bucket was non-filtering, at a point just above the bucket. In those cases nearly all the catch was found above the closing line. If this applies to smaller vertical nets, it is clear that should a blind bucket be used on short hauls where the length of water column inside the net is an appreciable fraction of the length of water column fished, then there will certainly be an increased tendency to lose organisms from the catch.

We have emphasized the importance of the accumulator spring and steam winch ensuring the rapid closing of the $\mathrm{N}_{70} \mathrm{~V}$. Although it is realized that the human arm in the operation of a hand winch such as used by Nicholls (I933) is a fairly effective accumulator, the reaction time of a strong spring must be considerably less than that of a man's arm released from a great strain, and it is no doubt on account of this, and the great flexibility of the steam winch, that the $\mathrm{N} 70$ throttles so rapidly compared with the International net (Barnes, 1949, fig. 6). (It should of course be remembered that the hauling speed of the 'Discovery' net is twice that of the International net.)

One final point that might be mentioned is the form of the closing rope. In the $\mathrm{N}_{70}$, this is a bight of rope extending down from the release gear and encircling the net. Some authors (e.g. Ostenfeld \& Jespersen, 1924), recommend the use of a single line descending from the release gear and forming a running noose, around the net. With this, obviously, there is much more slack to be taken in before the net is throttled, and this method should certainly be avoided. 


\section{CONCLUSIONS}

The observations which are presented here cannot be regarded as conclusive proof of the infallibility of the Nansen closing method. They do show, however, that it is highly improbable that any significant loss of catch can occur if the method is applied in the way it has been to the 'Discovery' net. The latter differed from the International net in respect of its high filtration coefficient. The other mechanisms which help to avoid loss of catch are the filtering window in the bucket and the rapidity of closure which is effected by the efficient accumulator and the steam engine's capacity to adjust the speed of the winch automatically to the tension of the wire. We would, however, stress that we are in entire agreement with Barnes's findings as applied to the International net as Nicholls used it, and this must be looked upon as a warning against the use of catches, made with the Nansen method, for quantitative work, before ascertaining in what manner the hauls have been made.

It will be obvious that this work would have been impossible without the assistance of all our colleagues on board the R.R.S. Discovery II in the September and October-November cruises in I955. To them we should like to express our gratitude, and in particular to Mr Edgar French who made the majority of the net hauls while the photographs were taken. We are also indebted to the Director and Lieut.-Commander Terrell of H.M. Underwater Countermeasures and Weapons Establishment for the loan and guidance in the use of the underwater camera.

\section{SUMMARY}

The object of the work described in this paper was to find out if the Nansen closing method used with vertical net hauls can be reliable in quantitative plankton investigations.

Barnes has shown that the International net, which is a fine-meshed net, can lose (through the mouth) a significant part of the catch at the moment of closure by the Nansen method.

The net used by Barnes, however, is not comparable to the 'Discovery' net which has a much higher filtration coefficient and is used with gear which ensures that there is no relaxation of tension on the towing wire when the net is closed.

Underwater observations and films have demonstrated that closure is very rapid and that there is little doubt that the Nansen closing method can be quite reliable provided certain precautions are observed. 


\section{REFERENCES}

BARNES, H., I949. A statistical study of the variation in vertical plankton hauls, with special reference to the loss of the catch with divided hauls. F. mar. biol. Ass. U.K., Vol. 28, pp. 429-46.

HJORT, J. \& RUUD, J. T., I927. A method for the analysis and comparison of plankton samples. F. Cons. int. Explor. Mer, Vol. 2, pp. 28-37.

Kemp, S., Hardy, A. C. \& Mackintosh, N. A., I929. Objects, equipment and methods. 'Discovery' Rep., Vol. I, pp. I4I-232.

KÜNNE, CL., I929. Vergleich der Fangfähigkeit verschiedener Modelle von planktonNetzen. Rapp. Cons. Explor. Mer, Vol. 59.

MOTODA, S. \& ANRAKU, M., I955. The variability of catches in vertical plankton hauls. Bull. Fac. Fish. Hokkaido Univ., Vol. 6, pp. I52-75.

Murray, Sir J. \& HJoRT, J., I9I2. The Depths of the Ocean. London: Macmillan.

NANSEN, F., I915. Closing nets for vertical hauls and for horizontal towing. Publ. Circ. Cons. Explor. Mer, No. 67.

Nicholls, A. G., I933. On the biology of Calanus finmarchicus. I. Reproduction and seasonal distribution in the Clyde sea-area during 1932. F. mar. biol. Ass. U.K., Vol. I9, pp. 83-I09.

Ostenfeld, C. H. \& JeSPERSEN, P. 1924. Standard net for plankton collections. Publ. Circ. Cons. Explor. Mer, No. 84.

WIBORG, K. F., I948. Experiments with the Clarke-Bumpus plankton sampler and with a plankton pump in the Lofoten area in northern Norway. Fiskeridir. Skr. Havundersok., Vol. 9, No. 2.

\section{EXPLANATION OF PLATES I AND II}

These photographs are alternate frames from a $35 \mathrm{~mm}$ cine-film, taken at a speed of 24 frames/ sec. The time interval between each photograph is therefore $\frac{1}{12} \mathrm{sec}$. The point of impact of the messenger is on the 4 th frame. 

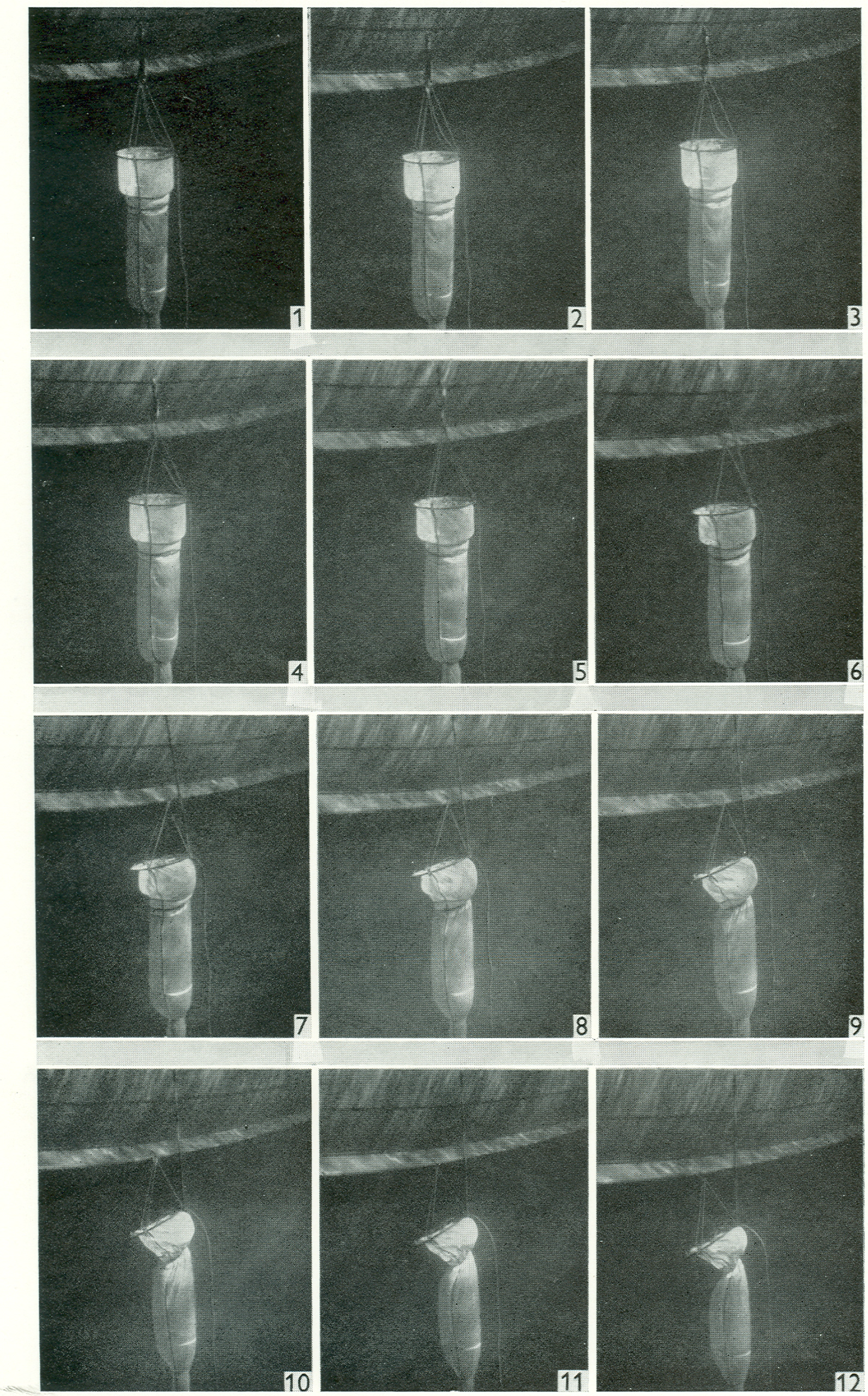

(Facing p. 492) 

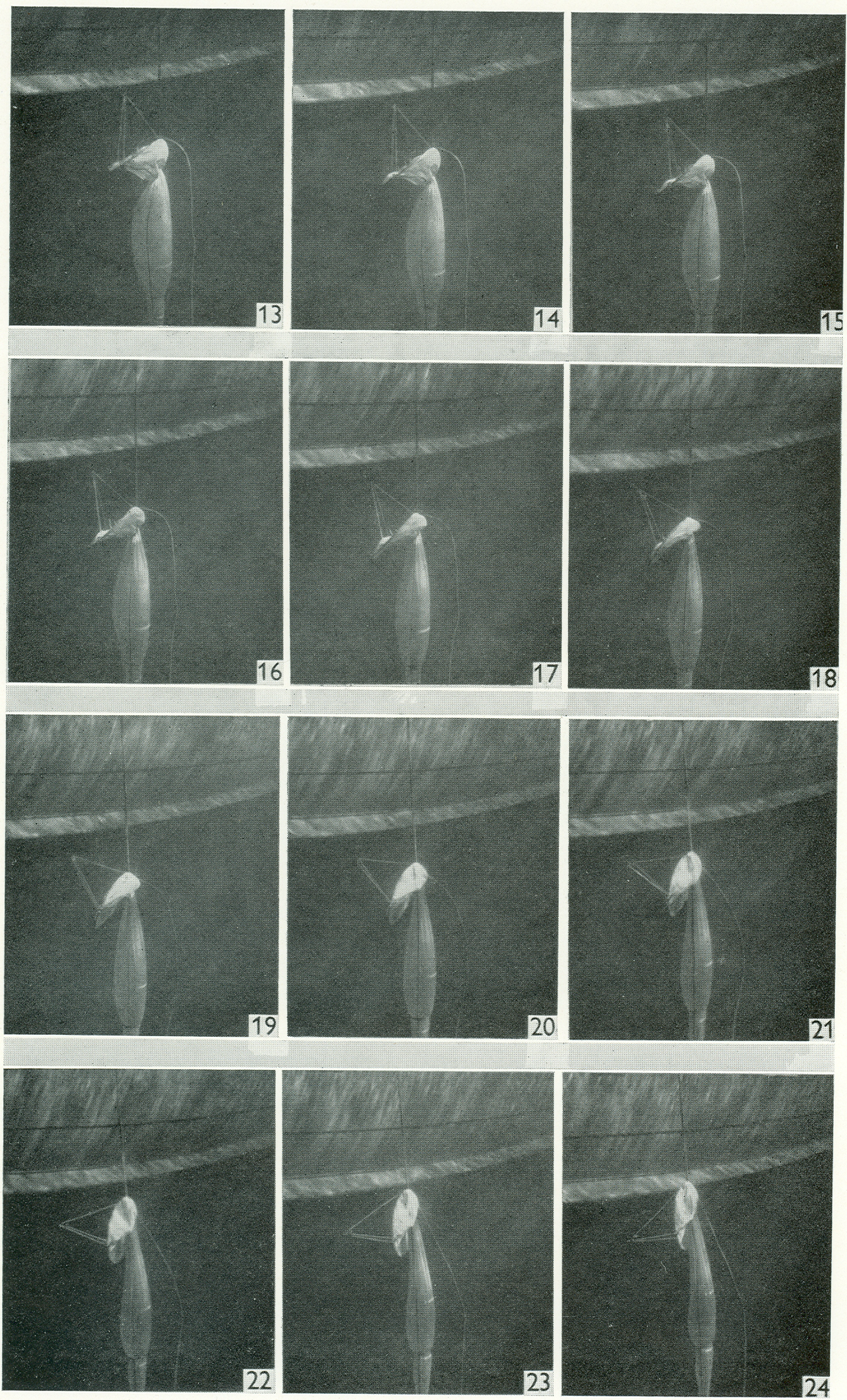